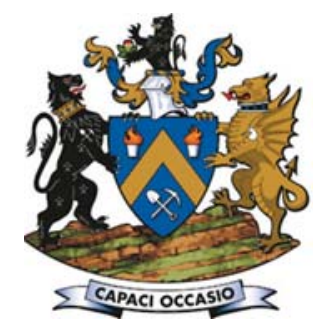

\title{
SAUCGA: The potential, role, and development of underground coal gasification in South Africa
}

\author{
by S. Pershad*t, M. van der Riet*t, J. Brand**, J. van Dyk*‡, \\ D. Love ${ }^{*}$, J. Feris ${ }^{* \#}$, C.A. Strydom* ${ }^{\circ}$, and S. Kauchali* ${ }^{*}$
}

\section{Synopsis}

This paper offers an introduction to and strategic context for the other papers included in this special UCG edition of the Journal of the Southern African Institute of Mining and Metallurgy. South Africa is facing long-term energy security challenges, brought about by a myriad of factors that are somewhat unique or exacerbated in the global context. Underground coal gasification (UCG) is a process used to produce synthesis gas from coal in situ, that is, in the coal seam. UCG is an emerging, advanced clean coal technology that offers a potential solution for these challenges, as it can cost-effectively and cleanly liberate vast coal resources in the country that currently cannot be economically exploited using traditional mining technologies. One of the tasks of the South African Underground Coal Gasification Association (SAUCGA) is to advance the development of UCG in South Africa by compiling a technology roadmap. This paper presents the initial findings of the SAUCGA Roadmap (Draft), and contextualizes the technology opportunities and challenges, stakeholders, and provides a basis from which to progress further plans for technology development. Firm development plans and deadlines are not yet possible due to the reliance of the UCG Roadmap on the higher level South African energy policy and regulatory framework. However, the draft roadmap has taken the first step of identifying these policies and stakeholders, and should be seen as the seed from which this embryonic technology and industry can be further developed.

Keywords

South Africa, underground coal gasification, UCG, coal mining, SAUCGA, roadmap. exploited using traditional mining

technologies.

The UCG opportunity arises in a period of energy transition, where utilizers of fossil fuels are under pressure to reduce emissions significantly to comply with international climate change commitments. In 2015 South Africa signed the Paris Agreement on climate change, which was developed under the auspices of the United Nations Framework Convention on Climate Change (UNFCCC). Furthermore, South Africa has a commitment to increasing the population's access to electricity, with one of the most significant hurdles being affordability. UCG technology offers potential solutions for these challenges. Research already completed and published by Eskom has highlighted this potential.

The South African Underground Coal Gasification Association (SAUCGA) is an independent, volunteer association established for the purpose of promoting the development of UCG in Southern Africa in the most appropriate, sustainable, and environmentally sound manner while recognizing the proprietary interests of participating bodies. It is thus fundamental for the efficient operation and ultimate value-add of SAUCGA to base its activities on a strategic planning document, which highlights the need for this roadmap that details a plan for UCG in South Africa, and therefore SAUCGA as well.

Furthermore, as with any emerging technology, strategic planning is essential to evaluate the current situation, what needs to be done now and in the future (bearing in mind the shifting goalposts), and the technology pathways to research and develop proportion of non-despatchable renewable energy sources, mounting environmental liabilities regarding defunct mining operations, and lastly but by no means less important, fluctuating exchange rates and energy commodity prices.

Correctly managed underground coal gasification (UCG) is an emerging, advanced clean coal technology that offers a potential solution for these challenges, as it has been shown to have the potential to cost-effectively and cleanly liberate vast coal resources in the country that currently cannot be economically

\footnotetext{
* South African Underground Coal Gasification Association, South Africa.

+ Eskom Holdings SOC Ltd., South Africa.

* African Carbon Energy, South Africa.

Golder, South Africa.

* Cliffe Dekker Hofmeyer, South Africa.

- North-West University, South Africa.

* University of the Witwatersrand, South Africa.

(C) The Southern African Institute of Mining and

Metallurgy, 2018. ISSN 2225-6253. Paper received Apr. 2018; revised paper received July 2018.
} 


\section{SAUCGA: The potential, role, and development of underground coal gasification in South Africa}

the technology in order to meet likely scenarios. This roadmap is constructed around these key elements.

The roadmap seeks to gather stakeholder viewpoints and consolidate and provide a consensus pathway forward for the development of UCG in South Africa for the period 2016 to 2040, aligning with the South African Integrated Resource Development Plan 2010 (Department of Energy, 2010), the South African Coal Roadmap (Fossil Fuel Foundation, 2013), and the National Development Plan (National Planning Commission, 2010).

Other key strategic documents (such as the South African Coal Reserves and Resources Report, and the South African Gas Utilisation Master Plan, Integrated Energy Plan, and Integrated Resource Development Plan) will be considered as they are published.

The intent is for this roadmap to be updated regularly, and alignment with these documents will be undertaken as they are published. The following key assumptions need to be defined, to set the context of this roadmap.

> UCG has a definite role to play in South Africa's future. The underlying assumption is that it can be appropriately engineered and proven to meet evolving requirements.

> This roadmap assesses the period 2016 to 2040.

> This roadmap focuses on UCG application within South Africa, but may be expanded to include neighbouring countries in Southern Africa.

> The current economic, environmental and social paradigms are the basis for this roadmap, with projections drawn from reference studies.

$>$ There will be no decline in South African market demand for electricity, liquid fuels, and chemicals, but demand will increase based on projections drawn from reference studies.

South Africa has developed an Integrated Resource Plan 2010 (Department of Energy, 2010) that projects that the energy mix will evolve in the period 2010 to 2030 to cater for a reduced role of coal (from about $89 \%$ in 2015 to $56 \%$ in 2030), replacement capacity, and growth in demand. This plan has been promulgated for the period 2010 to 2030, and IRP updates have been drafted with the most recent being the
IRP 2016, which has undergone public comment and is still awaiting finalization. As such, the IRP 2010 remains the only promulgated IRP plan at present, and is therefore the country's reference resource plan. It is noted, that in the absence of a 2018 updated and accepted IRP, the assessment of UCG's potential capacity and role in comparison with other competing energy sources is difficult. It is also widely acknowledged that coal will play a significant, albeit reducing, role in South Africa's energy mix until 2050. UCG offers a better, cleaner coal usage alternative.

The IRP 2010 seeks to cap carbon dioxide emissions at $250 \mathrm{Mt} / \mathrm{a}$. This cap therefore dilutes coal's predominance over the next decades, as seen in Figure 1. It must be noted, however, that coal will still play a significant role until at least 2050, and if the retirement of the ageing generating fleet is considered then new coal-fired generating capacity is going to be required. Given the environmental pressure, such capacity will need to be based on sustainable coal technology solutions, which include UCG. There are many coal-based technology options under development that could significantly reduce coal emissions, thereby displacing other energy resources by being able to compete in terms of emissions and cost.

\section{UCG as a mining method}

UCG is not a new technology. In fact, references to UCG can be found dating from the late $1800 \mathrm{~s}$, and the earliest US patented posting of UCG as an alternative mining method was filed in 1901.

The main difference between UCG and more conventional surface gasification projects is that in the latter, gasification occurs in a manufactured reactor, whereas the reactor for a UCG system is the natural surrounding geological formation (typically consisting mainly of sandstone or dolerite) containing unmined coal. In UCG, coal is gasified in situ and converted into syngas, which is then transported to the surface via a specially designed and drilled production borehole. The conversion of the coal to syngas is achieved through a partial combustion process controlled by the injection of oxygen $\left(\mathrm{O}_{2}\right)$ into the coal seam through an injection well.
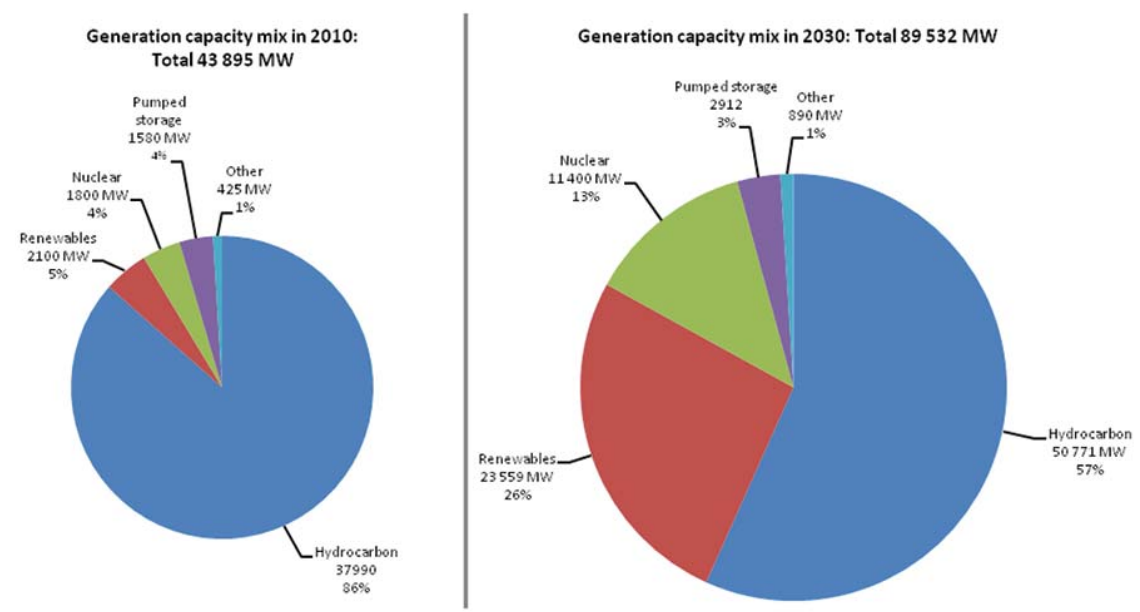

Figure 1-The size and mix of South Africa's power generation capacity, 2010-2030 (Department of Energy, 2010) 


\section{SAUCGA: The potential, role, and development of underground coal gasification in South Africa}

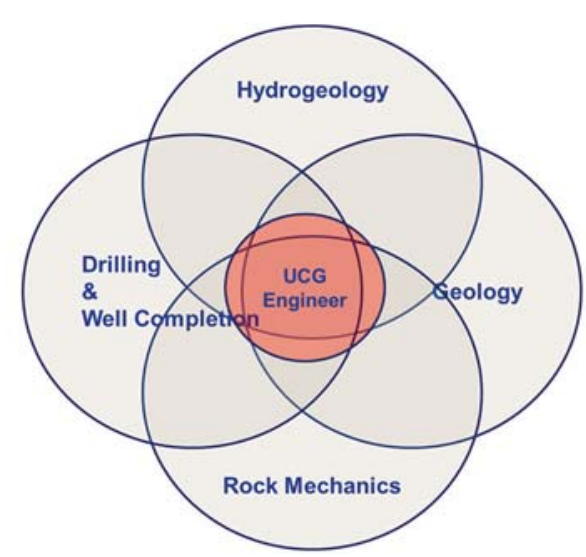

Figure 2-Key skills and disciplines involved in UCG-related underground activities (Pershad, 2016)

UCG principally requires mining and geoscience skills to be integrated in a multidisciplinary team to plan, design, operate, and rehabilitate a UCG gasifier, as illustrated in Figure 2. The core skills and sciences required are: geology; hydrogeology; rock mechanics; drilling and well completion; and UCG mining engineering and technology (which includes mining engineering, chemical engineering, and gasification expertise).

\section{Process concept}

UCG is similar to surface gasification, and is a chemical process that converts solid or liquid fuels into a clean combustible gas (synthesis gas or syngas) consisting of carbon monoxide $(\mathrm{CO})$, hydrogen $\left(\mathrm{H}_{2}\right)$, methane $\left(\mathrm{CH}_{4}\right)$, and carbon dioxide $\left(\mathrm{CO}_{2}\right)$. The ratios of these components in the final product syngas depends on the chemical composition of the fuel (coal), the type of reactant (air, oxygen, $\mathrm{CO}_{2}$, and steam) the ratios used in the process, and the operating conditions. Clean syngas can be used for synthesis of transportation fuels and chemicals, production of hydrogen, direct reduction of metal ores, electricity generation, or a combination of these.

The fundamental difference between UCG technology and surface gasification is that UCG enables coal to be gasified in situ. The conversion of the coal to syngas is controlled by the injection of oxygen into the coal seam through the injection well.

A borehole is drilled through the overburden down to the coal seam, which is then ignited. Oxygen or oxygen-enriched air is injected to feed the process and drive the gasification reactions that produce a syngas mixture. These gases are collected by the production borehole for utilization at the surface. UCG creates a cavity below ground filled with ash, the size of which depends on the rate of water influx from the water table, the heat content of the coal, the location and shape of the injection and production wells, and the thickness of the coal seam.

There are two main commercially available UCG methods. The oldest method uses alternating vertical wells for injection and production combined with reverse combustion linking to open up internal pathways in the coal. This process was used in the Soviet Union from the 1940s, and was later tested in Chinchilla, Australia and by Eskom in South Africa. The second method, which was developed in the USA in the 1980s, employs dedicated in-seam boreholes, drilled using directional drilling and completion technologies adapted from the global oil and gas industry. It incorporates a moveable injection point method known as CRIP (controlled retraction injection point) and generally uses air or oxygen-enriched air for gasification.

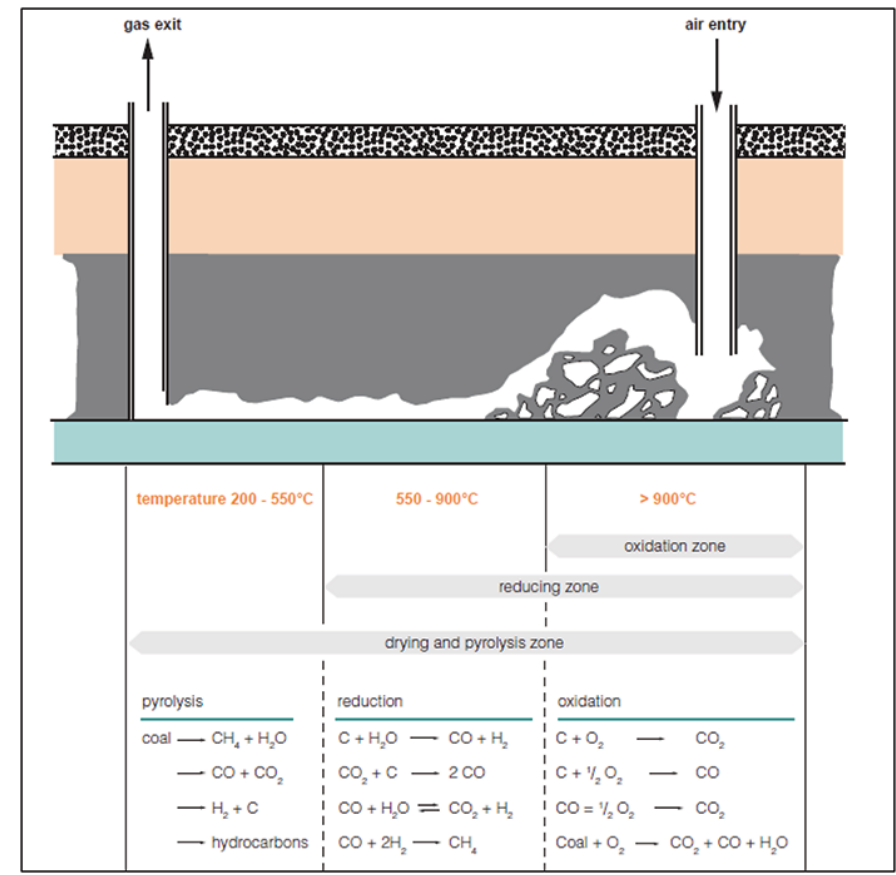




\section{SAUCGA: The potential, role, and development of underground coal gasification in South Africa}

\section{Gasification}

A gasification process must satisfy chemical constraints based on the stoichiometry of the coal gasification reactions and the energy requirements to sustain these reactions. Gasification of char produced by the devolatilization process involves chemical reactions between primary reactants, i.e. carbon in the char, oxygen, and steam, as well as a number of reactions between primary and secondary reactants, i.e. $\mathrm{CO}, \mathrm{CO}_{2}$, and $\mathrm{H}_{2}$. The basic gasification reactions are illustrated in Figure 3.

\section{Advantages of UCG}

UCG has considerable environmental benefits. The syngas is generated deep underground inside the coal seam, while the ash in the coal mostly stays in the seam. About $80 \%$ of the energy in the coal can theoretically be extracted as syngas, making UCG a very efficient mining process. At the same time, no persons are required underground, which offers safety benefits. UCG is not just more efficient and safer, but also offers the following advantages.

- UCG can be combined with large-scale combined-cycle plant to reach energy efficiencies exceeding $50 \%$ compared to the current $35 \%$ efficiencies obtained in subcritical pulverized fuel boilers.

- UCG produces less particulate emissions, thus the process requires minimal ash handling, and there is little or no leaching of trace elements from ash when operated correctly.

> UCG can monetize economically un-mineable coal that would otherwise be lost to the country's economy. Approximately only one-quarter of South African coal reserves are economically and technically recoverable with current conventional mining methods (Barker, 1999).

> UCG deployment can create new high-value jobs in the drilling, gas processing, and gas engine maintenance industries.

- UCG projects can be located in economically depressed areas of South Africa, often far from current mining areas.

> No chemicals are injected into the UCG process as only air and water are required for gasification.

- Fracking is not required and no fracking chemicals are injected to create the boreholes.

> The UCG syngas is already in a form that can be further monetized to liquid chemicals or fuels, or the syngas can be separated to obtain basic chemicals such as hydrogen, carbon monoxide, and methane.

> The form of sulphur present in the syngas allows for economic recovery of elemental sulphur (which can form part of the chemicals portfolio).

> Technologies for $\mathrm{CO}_{2}$ removal (for future capture and storage) from the syngas are well matured.

- The UCG reactor can be operated to maximize methane production (if required by the market) with the rest of the syngas rich in $\mathrm{CO}-\mathrm{H}_{2}$ for further production of methane or other chemicals.

\section{UCG in the global context (Blinderman, 2016)}

A long period of UCG development, spawned by the energy crisis that started in 1973, was completed by the Rocky Mountain 1 trial in the USA in 1988 and the European UCG trial in Spain in 1992. Following several years of lull and uncertainty, the Chinchilla UCG project in Australia marked the beginning of new era of UCG development in Australia, New Zealand, South Africa, Europe, Canada and the USA. Spanning almost 20 years, this latest stage of UCG development was distinguished by a preponderance of privately funded projects with a significant share of the capital raised from stock markets.

It appears that this latest stage of UCG development has suffered considerably from the drop in fossil fuel prices in world markets, and from the commodity market slowdown. Whereas the reduced oil and natural gas prices seem to have affected new and existing UCG projects by decreasing the projected sale price of UCG products, the corresponding precipitous drop in coal price reduced the revenue streams of many UCG proponents to the extent that they could no longer invest in new UCG projects. An example of the latter was the 2012 shutdown of the Huntly West UCG pilot plant in New Zealand.

The economic slowdown led to the need for partnering with the Majuba UCG pilot project in South Africa, and reduced economic performance due to the suppressed energy prices in, for instance, North American markets led to closure of the Swann Hills and Parkland County UCG projects in Canada.

The other factor limiting UCG activity worldwide is the lack of preparedness of environmental regulations and misunderstanding and misinformation on UCG within some environmentally concerned communities, caused no doubt by the scarcity of factual information on UCG and confusion with fracking of oil shales. This regrettable state of public awareness may have contributed to the reluctance of local authorities to approve new UCG projects in several jurisdictions.

In the meantime, in many parts of the world where there is no sign of pending additional energy sources (including shale oil and gas), UCG development remains an imperative for supplying affordable energy and hydrocarbon feedstock for local industrial and retail markets. Examples of such locations are South Africa, India, and Pakistan.

It is therefore quite clear that a new stage of UCG development must be based on a solid foundation of specific and comprehensive regulation covering environmental protection, potential conflicts of ownership of mineral and petroleum rights, royalty regimes etc.

Many countries with large coal resources but which lack conventional oil and gas are now focusing on proposing detailed UCG regulatory frameworks. Among them are China, India, and South Africa. These efforts are spearheaded by appropriate governmental offices and there are indications that the regulations may be finalized within the next 2-3 years.

There are several UCG projects that are now being prepared in anticipation of pending regulations.

> In China, there are four proposed UCG projects targeting power generation, and supply of syngas to a 


\section{SAUCGA: The potential, role, and development of underground coal gasification in South Africa}

Fischer-Tropsch facility and a synthetic methane plant. Only limited information has been made available by the developers.

> In India, the central government has specified a pathway for government-owned corporations to develop UCG plants at a pilot scale. The coal blocks that would be allocated to these companies for UCG development have been identified; and work should start in earnest once the regulations are available.

- In South Africa, there are at least three projects that are now anticipating water use regulations governing 'unconventional' gas (viz. shale gas, coalbed methane, and UCG). They include the Majuba UCG partnership development by Eskom, the 50 MWe Theunissen UCG project by African Carbon Energy, and the Sterkfontein project developed by Oxeye Energy.

There are furthermore several UCG projects under way in jurisdictions where existing regulations appear to support UCG development. These areas include India, South and Central Australia, Indonesia, Alaska, Canada, and the UK.

Apart from UCG projects pursuing clear commercial outcomes, there a number of UCG projects that are conducted primarily for $R \& D$ purposes. These include the recently concluded European TOPS research project that considered technology options for coupled UCG and $\mathrm{CO}_{2}$ capture and storage and HUGE, the Hydrogen Oriented Underground Coal Gasification for Europe project development largely by Polish researchers in Główny Instytut Górnictwa. The demonstration installation was built on the premises of CCTW Mikołów in the Underground Testing Range.

\section{UCG in the South and Southern African context}

Eskom Holdings SOC Limited (Eskom) has played a significant role in contributing to the research and development of UCG in the Southern African region by, among others, demonstrating the technical feasibility of the technology, as well as the potential economic feasibility of utilizing UCG technologies in exploiting un-mineable coal resources to produce syngas and other by-products for various downstream uses. These scientific findings are being prepared for publication.

Southern Africa still has significant coal resources, the majority of which are deemed uneconomic to mine due to depth or other technical or market factors. UCG offers a potential solution for accessing these abundant resources in a cost-effective and clean manner.

This technology opportunity arises in a period of energy transition, where fossil fuel users are under pressure to reduce emissions significantly to comply with international climate change commitments. In the local context, in 2015 South Africa signed the Paris Agreement on climate change, which was developed under the auspices of the United Nations Framework Convention on Climate Change (UNFCCC). Furthermore, South Africa has a commitment to increasing the population's access to electricity, with one of the most significant hurdles being affordability. UCG is a coal technology that offers potential solutions for these challenges.

In Southern Africa, Eskom has for the past 16 years taken a leading role in investing in the development of the first UCG facility in Africa (Pershad, 2016), based on the technology of Ergo Exergy Technology Inc. (Ltd).

Eskom's review of existing data and Majuba-specific tests led to the construction of a $5000 \mathrm{Nm} 3 / \mathrm{h}$ pilot plant, which achieved ignition and first flaring of gas on 20 January 2007. From a research and development perspective Eskom demonstrated the following:

> The technology provides cost-competitive fuel for future power generation. It derives this fuel from local, unused coal resources shielded from international market forces.

> It has been qualitatively proven that the technology works, and is able to extract value from one of the most geologically complex coalfields in South Africa.

> There is a need to further quantify the performance of UCG technology, so that it can be optimized.

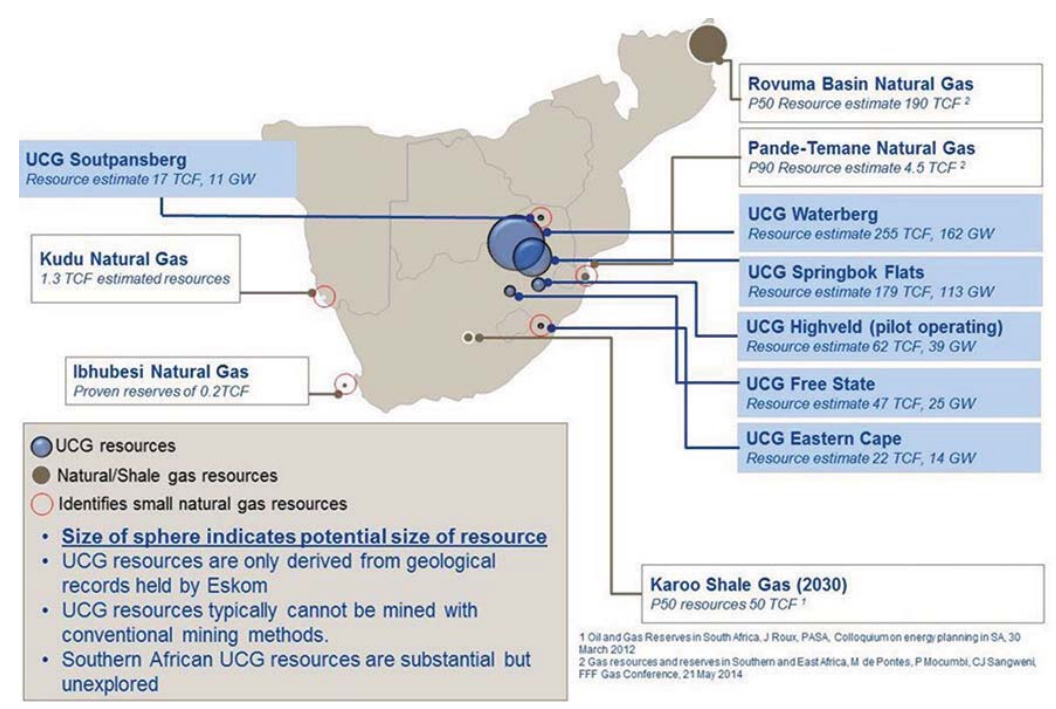

Figure 4-Map showing potential UCG sites in South Africa (Pershad, 2017) 


\section{SAUCGA: The potential, role, and development of underground coal gasification in South Africa}

> The Eskom Board supports the technology, but due to Eskom's current financial constraints a partner will be sought to further commercial development.

> Eskom will in parallel shut down and rehabilitate the initial Majuba gasifier as part of the original research intent.

Research already completed by Eskom has highlighted the technology potential. Eskom intends to complete the final stage of the research and prove the commercial viability of the technology in the next phase of development. The goal will be to achieve the same emissions footprint and cost as the supercritical pulverized fuel technology utilized in Eskom's new Medupi and Kusile power stations. The commercialization will coincide with the demand for new coal-fired generating technology, as per the Integrated Resource Plan (Department of Energy, 2010).

It must be noted that there are several different UCG technologies, apart from Ergo Exergy's technology, being utilized by other UCG developers.

The other proposed UCG projects in South Africa and to a lesser extent, the rest of the Southern African region (Mining Weekly, 2013) are African Carbon Energy and, more recently, Oxeye Energy, who are actively pursuing the potential application of UCG technologies in exploiting un-mineable coal resources in South Africa.

African Carbon Energy (Africary) is pursuing the development of a UCG facility in Theunissen, Free State Province. Africary intends to develop a UCG power generation facility which will form part of the Gas to Power Independent Power Producers Programme of the Department of Energy.

Oxeye Energy concluded a memorandum of understanding with Ergo Exergy for the potential development of a UCG facility for the generation of electricity. Oxeye is currently completing a conceptual study on the application of UCG technology in the Sterkfontein area, Bethal, Mpumalanga Province.

Figure 4 depicts the various potential sites for UCG in South Africa,, illustrating the significant potential.

Despite the concerted development of UCG in South Africa there are still major challenges holding back the commercial uptake of UCG technology. SAUCGA has identified these as follows.

> In South Africa, UCG was declared a controlled activity in 2015 by the Department of Water and Sanitation (DWS). The DWS has still to issue the water use license (WUL) control guidelines for applicants. Other unconventional gas sources such as shale gas and coalbed methane also face this regulatory hurdle.

> A core, critical, and widely accepted suite of energy framework policies for South Africa that would attract investors in mining, electricity, and energy. In this regard the revised Mining Charter, Integrated Energy Plan (IEP), Integrated Resource Plan (IRP), and Gas Utilisation Master Plan (GUMP) are eagerly awaited. These anchor policies will set the framework for projects and investments to be made with confidence and certainty.

> Electricity and energy demand growth synonymous with growing South African industrial and economic activity.
> To a lesser degree, the necessary skills and experience to advance a first-of-a-kind (FOAK) technology project through regulatory, project management, and financing systems that are created predominantly for known, offthe-shelf technologies. Similarly, risk management practices are not complementary to the evolution of embryonic technology, particularly where that technology development is at a larger scale, operating in the environment beyond laboratory scale, which requires licensing and permitting against an extensive body of knowledge that substantiates granting of licenses. This sets up a classic chicken-egg conundrum between the regulatory and $R \& D$ processes.

> The adverse environmental outcomes of some UCG projects around the world, and the corresponding public perception.

However, before the above issues can be addressed, stakeholder interest, engagement, and buy-in needs to occur in order to engage in a serious, concerted path of technology advancement and development. The current draft UCG roadmap is the first step in resolving these issues.

Industry knowledge suggests that countries such as Namibia, Botswana, and Mozambique have potential for the application of UCG technology to un-mineable coal resources.

\section{Potential UCG applications in South Africa \\ Power generation}

From 2007, South Africa faced a decade of electricity shortages due to a variety of reasons, and this has resulted in load shedding and a corresponding constraint on economic activity and growth. The electricity price has also increased significantly in the interim. There is now a theoretical overcapacity situation in 2018, as the Medupi, Kusile, and Ingula units are being commissioned. The excess capacity, however, has had the unintended consequence of allowing more time to review all primary energy sources and generating technologies.

In this regard, South Africa is unfortunately not blessed with conventional onshore natural gas resources and development of unconventional gas resources like shale gas and coal bed methane remains to be realized. While conventional natural gas offers a cleaner fuel for power generation, commodity price fluctuations present a risk to the South African economy.

South African is blessed with abundant coal resources, and the Integrated Resource Plan (Department of Energy, 2010) as well as the South African Coal Roadmap (Fossil Fuel Foundation, 2013) accounts for the continued use of coal in the electricity industry planning for the next 50 years.

In May 2015, the South African Department of Energy (DoE) further recognized the potential role that UCG-based power generation could play by requesting information on gas-based electricity generation capacities and time periods via a 'Request for Information'. Under this RFI, UCG was identified as a 'Gas' option, from the following definition: Gas - Any of: (i) natural gas which occurs naturally underground (either from a conventional gas field or an unconventional gas field including shale gas and coal bed methane ("CBM")) or (ii) synthesis gas ("syngas") 


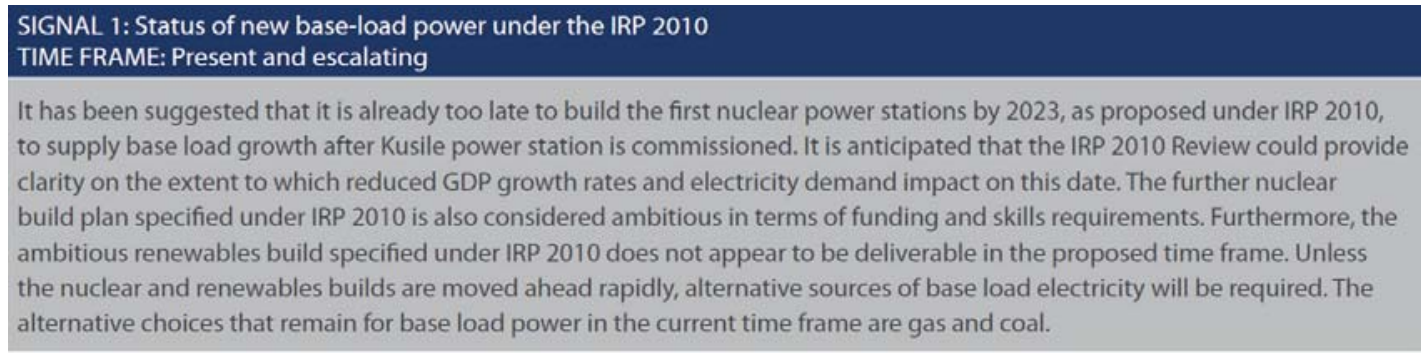

Figure 5-South African Coal Roadmap (Fossil Fuel Foundation, 2013) - Status of New Base Load Power Generation

\begin{tabular}{|c|c|}
\hline $\begin{array}{l}\text { BOX 2: PERSPECTIVES ON WHAT CONSTITUTES A } \\
\text { FLOURISHING SOUTH AFRICA }\end{array}$ & $\begin{array}{l}\text { - Water quality, land transformation and implications } \\
\text { for biodiversity; }\end{array}$ \\
\hline $\begin{array}{l}\text { The aim of the South African Coal Roadmap was to explore } \\
\text { how best the coal value chain can contribute to a flourishing } \\
\text { South Africa. The analysis thus explored the implications of } \\
\text { the scenarios in terms of the following indicators: }\end{array}$ & $\begin{array}{l}\text { - Solid waste generation; } \\
\text { - Implications for coal resources and reserves in } \\
\text { South Africa; } \\
\text { - Non-greenhouse gas emissions. }\end{array}$ \\
\hline $\begin{array}{l}\text { - Electricity generation infrastructure investment cost; } \\
\text { - Electricity generation cost; } \\
\text { - Domestic coal price and revenue from local sales; } \\
\text { - Export revenue; } \\
\text { - Carbon intensity of electricity generation; } \\
\text { - Global competitiveness; } \\
\text { - Energy security; } \\
\text { - Employment and other socio-economic implications; } \\
\text { - Water demand and provision; } \\
\text { - Transport and water infrastructure requirements; } \\
\text { - Greenhouse gas emissions; }\end{array}$ & $\begin{array}{l}\text { Under no single future or scenario can the performance } \\
\text { in all of these indicators be optimised and prioritising } \\
\text { certain outcomes necessitates compromises to be made. } \\
\text { The principal objective is one of sustainable development: } \\
\text { enabling the current generation of South Africans to prosper, } \\
\text { without compromising the ability of future generations to } \\
\text { do the same. It is recognised that reducing the impact of } \\
\text { the energy sector on the environment requires substantial } \\
\text { investment, but this will result in lower environmental } \\
\text { impacts now and into the future. At the same time, provision } \\
\text { of affordable and reliable energy today is critical in meeting } \\
\text { our development challenges. The scenarios provide the } \\
\text { opportunity to understand the magnitude and direction of } \\
\text { these trade-offs. }\end{array}$ \\
\hline
\end{tabular}

Figure 6-South African Coal Roadmap (Fossil Fuel Foundation, 2013) - Perspectives of a flourishing South Africa

including underground coal gasification ("UCG"), or conventional coal gasification as part of integrated gasification and combined cycle ("IGCC") gas technology or (iii) Liquefied Natural Gas ("LNG") or Compressed Natural Gas ("CNG") or (iv) liquefied petroleum gas ("LPG");

The South African Coal Roadmap (Fossil Fuel Foundation, 2013) considers the short-term signals illustrated in Figure 5, with respect for electricity generation under the IRP 2010.

The 'already too late' situation that was referenced to July 2013 can now be surmised as being very late in 2018. The Coal Roadmap goes further to describe the perspective on what constitutes a flourishing South Africa. From Figure 6, it is evident that electricity generation and infrastructure investment costs as well electricity generation costs are significant perspectives to be considered. UCG is a key technology that directly supports coal mining, and hence a flourishing South Africa.

The National Development Plan (National Planning Commission, 2010) explicitly identifies underground coal gasification technology under its Chapter 4 - 'Economic Infrastructure' (pages 163, 171, and 181) for the following South African context:

'South Africa needs to maintain and expand its electricity, water, transport and telecommunications infrastructure in order to support economic growth and social development goals. Given the government's limited finances, private funding will need to be sourced for some of these investments.'

'Policy planning and decision-making often requires trade-offs between competing national goals. For instance, the need to diversify South Africa's energy mix to include more renewable energy sources, which tend to be variable in terms of production, should be balanced against the need to provide a reliable, more affordable electricity supply.'

With specific reference to coal, UCG, and electricity, the NDP makes the following comment:

'Cleaner coal technologies will be supported through research and development and technology transfer agreements in ultra-supercritical coal power plants, fluidised-bed combustion, underground coal gasification, integrated gasification combined cycle plants, and carbon capture and storage, among others.'

It is thus evident that UCG for electricity generation in South African is in alignment with the IRP 2010 (Department of Energy, 2010), SA Coal Roadmap (Fossil Fuel Foundation, 2013), National Development Plan (National Planning Commission, 2010), and DoE gas industry intentions.

Critically, UCG for electricity generation in South Africa is under a clear, direct, and explicit developmental mandate. 


\section{SAUCGA: The potential, role, and development of underground coal gasification in South Africa}

\section{Liquid fuels and chemicals production}

The production of low-cost syngas may provide a lower cost route for electricity generation, but can also lead to the development of new lucrative chemical industries, with associated jobs and skills. A crucial factor for unlocking large-scale usage of UCG syngas will be the advancements made in catalysis for Fischer-Tropsch and direct syngas-toolefins processes.

Key issues to be considered for plants producing liquid fuels and chemicals are:

> The quantity of nitrogen in the syngas and the need to include an air separation step prior to gasification.

> The pressure and temperature of the syngas, requiring addition compressors or heat exchangers for downstream conversions.

> Flexibility of the downstream conversion processes (syngas to liquid fuels/chemicals) to utilize a variety of syngas compositions derived from a UCG process specifically the $\mathrm{H}_{2}$ :CO ratio required for downstream processes.

> Storage and transportation of the products, as well as handling of waste effluent (e.g. process water).

> The level of complexity (in plant configuration and operations) specifically for UCG sites that are physically far from service providers and markets.

> The need for, degree, and economics of gas clean-up for the protection of downstream catalytic processes. Generally, all processes for syngas conversion are catalytic in nature.

\section{Polygeneration systems}

With the South African coal-fired power sector facing potentially fatal challenges, it would be forward thinking to consider the possibility of producing not just power, but also a range of products from coal gasification. The products (in addition to electricity) may include cooling, heating, chemicals (hydrogen, $\mathrm{CO}_{2}$, methanol, Fischer-Tropsch liquids, ammonia etc.). The possibilities of producing energy, fuels, and other products through a polygeneration system are shown in Figure 7.
UCG syngas derived from an air-blown gasifier is typically of low calorific value, between 3 and $5 \mathrm{MJ} / \mathrm{m}^{3}$. This low calorific value gas, while reducing the capital cost of syngas production, leads to a number of issues.

Firstly, the lower energy content implies that compressing and long distance transportation is uneconomic, and secondly, the equipment for power generation is less available. The opportunity for liquid fuels and chemicals production (during minimum power demand) is therefore worth consideration. Here, the UCG reactors may operate at full capacity to produce syngas, and at off-peak electricity demand times the syngas can be diverted to a liquid fuels production plant. UCG thus offers the flexibility of producing multiple commercial products.

It is acknowledged that liquid fuel is considered to be a peaking fuel, enabling the power plant to operate during peak demand, with liquids produced during off-peak times. However, there is still a debate as to whether the liquid should be methanol or Fischer-Tropsch derived liquids (naptha and middle distillates). The advantage of methanol is that it is a single product of immense value as both a chemical and a fuel. However, the methanol reaction is thermodynamically equilibrium-limited, requiring high pressure and a large internal recycle.

Fischer-Tropsch synthesis, on the other hand, is not equilibrium-limited, and can operate with low partial pressures of hydrogen and carbon monoxide. The liquids produced can be tailor-made (via catalysis) to produce large amounts of naphtha and middle distillates that can be stored or used. Fischer-Tropsch products generally require further upgrading to be commercially acceptable by the market. .

\section{Environmental impacts of the UCG value chain}

UCG takes place deep underground in unexposed coal seams (refer to Figure 8). A residue of slag, ash, and salts remains in the gasifier cavity in the coal seam. UCG is considered a cleaner energy source as the known effect on the environment is much less than that of the mining and combustion of thermal coal. It also generates far fewer greenhouse gas emissions compared to conventional coal mining. It has, however, various potential risks, among

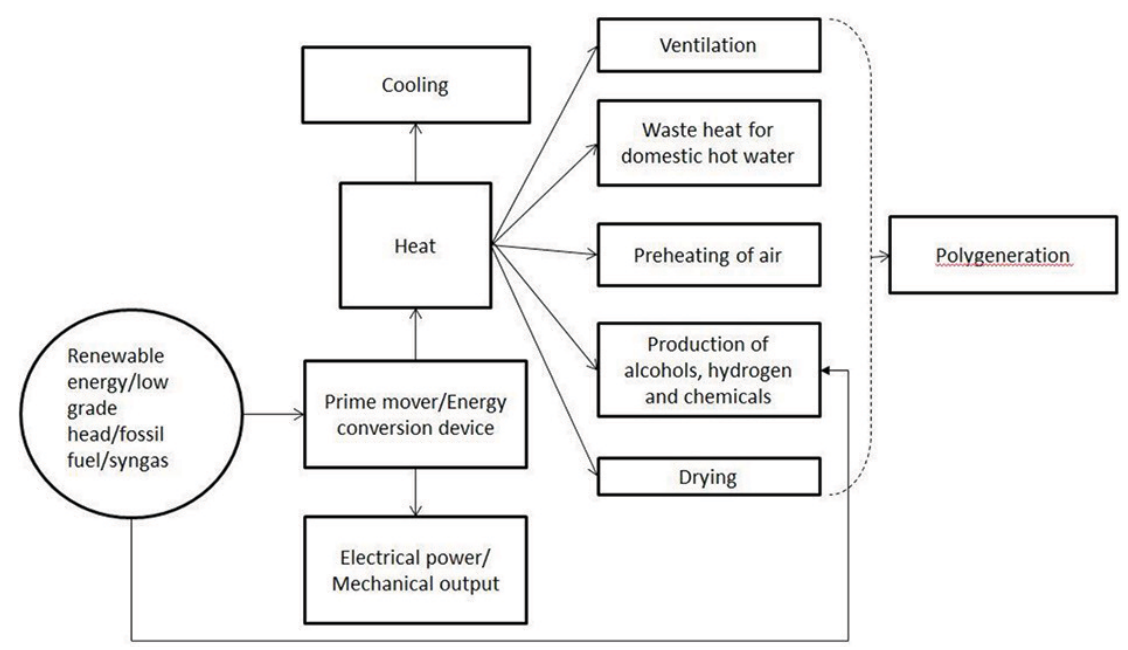

Figure 7-Pathways for polygeneration systems (adapted from Murugan, 2016) 


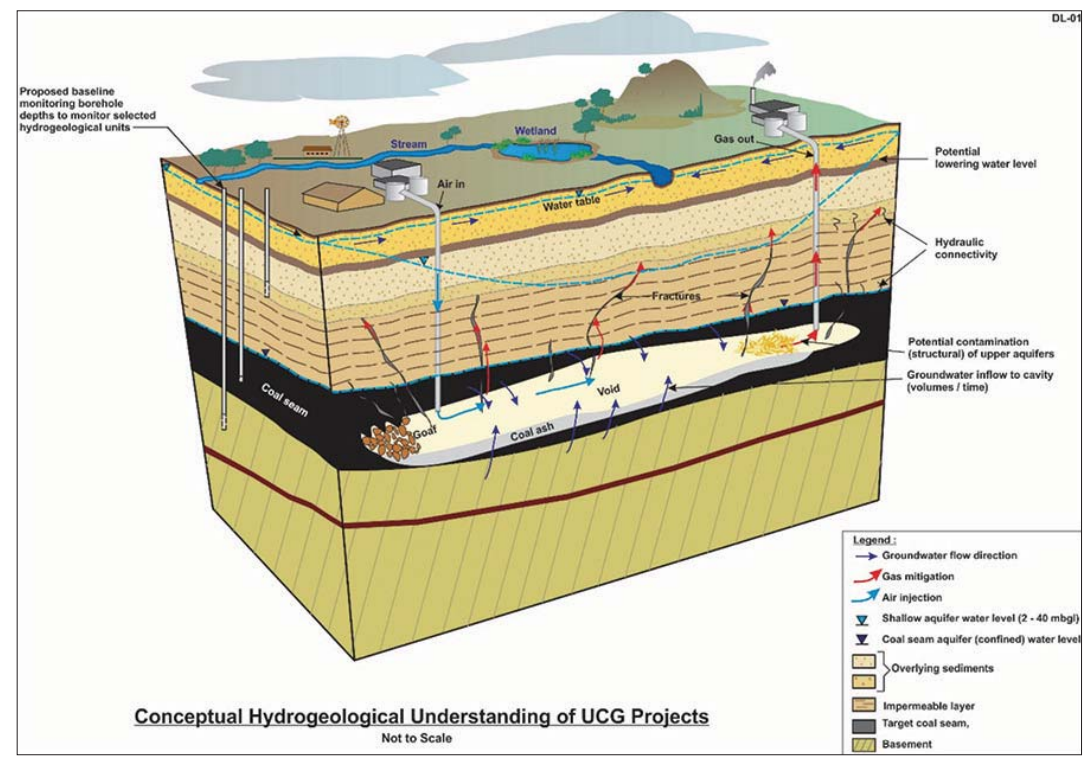

Figure 8-Schematic diagram of UCG (Love, 2016. @ Golder Associates Africa 2015, reproduced with permission)

which the subsidence of the ground surface and potential groundwater contamination are the biggest concerns.

\section{Groundwater consumption}

The gasification reaction takes place underground within the gasification channel, within the underground cavity in the underground portion of the gasifier (Figure 8). The pressurized gasifier operates at high temperatures of $650^{\circ} \mathrm{C}$ to $1600^{\circ} \mathrm{C}$. The process consumes water in the coal seam aquifer as well as moisture within the underburden and overburden layers, leading to a groundwater cone of depression. An external water source is not generally required for the UCG process, except in exceptional cases where very low groundwater levels are insufficient to meet the UCG water requirements.

\section{Groundwater pollution prevention}

Studies of (above-ground) gasification residues suggest that the residue is mainly an aluminium-calcium silicate slag with tars and unburnt coal minerals (Choudhry and Hadley, 1996; Ginster and Matjie, 2005). However very little information is available on the heavy organic chemistry of the residual ash and salts, with most environmental studies focusing on the light organic fraction present in the condensate, including phenols, benzene, methylbenzene (toluene), ethylbenzene, dimethylbenzenes (xylenes), and polycyclic aromatic hydrocarbons (Liu et al., 2007; Smoli ski, et al., 2012a, $2012 b)$. The proportion of the light fraction remaining in the gasifier residue is also poorly understood.

The UCG process has two intrinsic source controls.

A proactive strategy, built into the design and proper operation of the UCG process.

> Vertical control: the gasifier must be below a suitable capping layer, for example an impermeable sill - this prevents loss of product and also contamination of any overlying aquifers.

> Vertical control: the gasifier operating pressure must be below the hydrostatic and lithostatic pressure at all times, so that the outward and upward 'push' of the operating gasifier pressure is counteracted by the downward pressure of overlying rock and water. Then pressurized water is not ejected upwards through solid rock and the groundwater flow direction is inwards towards the gasifier. Maintaining the gasifier pressure below hydrostatic and lithostatic pressure minimizes gas leaks from the gasifier and therefore ensures that minimal contaminants (phenol, benzene, etc.) leak out beyond the boundaries of the gasifier.

> Lateral control: the pressure gradient must be towards the cavity. A cone of depression caused by the gasification process consuming groundwater results in controlled ingress of groundwater used in gasification, and creates a pressure barrier against contaminant flow away from the gasifier, thus preventing egress of potential contaminants into the surroundings.

Reactive monitoring strategy (van der Riet et al., 2014; Love et al., 2014, 2015a, 2015b).

> Checking that there is no vertical migration of contaminants to shallow or upper intermediate aquifers.

> Checking that piezometric groundwater levels indicate that the cone of depression is being maintained and that the pressure gradient is in place.

> Checking that the operating pressure is below the hydrostatic and lithostatic pressure.

$>$ Separation of the coal seam from the lower intermediate aquifers by e.g. a dolerite sill.

During shutdown, the gasifier is depressurized and the groundwater naturally present around the coal seam is allowed to gradually flood the cavity. This dissolves some of the ash and salts, and the more saline groundwater may affect downstream groundwater compositions by diffusion or by advection once the water table has stabilized and regional groundwater flow has resumed. 


\begin{tabular}{|c|c|c|c|}
\hline \multicolumn{4}{|c|}{ Groundwater zones in UCG and conventional mining (Love, et al., 2014b) } \\
\hline $\begin{array}{l}\text { UCG zone during } \\
\text { operations }\end{array}$ & Conventional mine equivalent & Conceptual basis & Monitoring purpose \\
\hline Production & $\begin{array}{l}\text { Underground mine workings or open } \\
\text { pit - 'process water' }\end{array}$ & Operational area & $\begin{array}{c}\text { Observe levels of 'process water' } \\
\text { against operations summary }\end{array}$ \\
\hline Process Control & $\begin{array}{l}\text { Safety zone around mine } \\
\text { workings or open pit }\end{array}$ & $\begin{array}{l}\text { Buffer zone for early warning } \\
\text { of any problems }\end{array}$ & $\begin{array}{l}\text { Monitor for significant changes } \\
\text { in early warning indicators }\end{array}$ \\
\hline Compliance & External environment & $\begin{array}{l}\text { Area expected to be unaffected } \\
\text { by UCG operations }\end{array}$ & $\begin{array}{l}\text { Compliance required with } \\
\text { agreed water quality standards }\end{array}$ \\
\hline
\end{tabular}

The monitoring strategy indicated in Table I is therefore necessary.

\section{Subsidence}

Subsidence caused by UCG processes can impact on the groundwater flow and levels due to the potentially modified groundwater recharge. This may affect nearby users as recharge flows preferentially through the subsided area.

It must be noted, however, that subsidence in UCG is a design choice rather than a risk, as it aids the UCG process. The following aspects must be borne in mind.

> Many UCG sites are at considerable depth, with competent rock bodies above the gasifier and the confining layer. In such cases, gasifier operations can be designed so that the depth of goafing does not result in significant vertical movement in the overlying layers, and consequently no subsidence occurs on surface.

> Alternatively, a UCG operation may be designed to cause subsidence at the end of the life of the gasifier, so that this takes place in a controlled fashion, followed by remediation of the surface environment while the operator is still on site. The increased groundwater recharge in this scenario can be used to accelerate the gasifier shutdown and clean-up process.

\section{Conclusions}

The availability of coal and sustainable role of coal mining is widely recognized within the South African context by most stakeholders in several key policy documents such as the National Development Plan (National Planning Commission, 2010), the IRP 2010 (Department of Energy, 2010), and the draft IRP 2016 and IEP 2016. Furthermore, the status and developmental needs of the coal industry were proposed in the Coal Roadmap (Fossil Fuel Foundation, 2013).

UCG development was initiated by Eskom, under the auspices of the DPE with close involvement of the regulatory departments DMR, DoE, and DWS. There are now several new UCG developers with specific projects under way, which in turn have generated interest from numerous other affected parties. An embryonic industry is being born!

Furthermore, UCG as a technology has received explicit prominence in the country's future energy plans, and is noted for its potential key role in energy provision. This acknowledgement requires the formulation of a strategy for research, development, and commercial implementation of UCG.

At the request of the DoE and DMR, SAUCGA was established for the specific purpose of promoting the development of UCG in Southern Africa. This roadmap details SAUCGA's plan for UCG in South Africa, and lays out a strategy for SAUCGA as well. It records the current situational analysis locally and internationally; what needs to be done now and in the future; and the technology pathways to research and develop the technology in order to meet likely scenarios moving forward.

Pioneering studies by Eskom Holdings SOC Ltd, their licensor Ergo Exergy Technologies Inc., and other specialist consultants have proven that the technology can effectively exploit the geologically difficult Majuba coal resources, which had been declared un-mineable in the 1980s with conventional mining technologies. The Eskom project has furthermore proven UCG compliance with strict mining and environmental standards, and advanced the technology by developing control and mitigation measures which reduce potential underground contamination risks. The UCG mining operation can be considered within three zones, with the production zone in the centre, surrounded by a process control zone and the compliance zone. All three zones enable efficient control and monitoring of the process.

UCG has been developed by Eskom for power generation, but is equally suited to providing feedstock for the liquid fuels and chemicals industries, as well as a hybrid polygeneration industry.

UCG presents a more efficient method of mining the three-quarters of South Africa's coal which is considered to be uneconomic using conventional mining technologies, due to depth and other issues. UCG therefore significantly extends the country's coal reserves.

South Africa requires growth in energy-intensive and mining industries to unlock the natural resources in the country, and in so doing unlocking the associated wealth and creating employment opportunities. This urgent need incentivizes the development of highly efficient and environmentally sustainable technologies such as UCG. 


\section{SAUCGA: The potential, role, and development of underground coal gasification in South Africa}

\section{Recommendations}

1. UCG has been piloted and has been successfully proven in the local context, which indicates an opportunity to depart from traditional thinking and conventional technologies used for energy projects. In particular, UCG offers an opportunity to move forward to commercialization, with the close involvement of the regulatory authorities, NGOs, I\&APs, and academia to fast-track learning, optimization, and policy formulation. It is recommended that UCG developers focus on actively ensuring such partnerships.

2. This brings with it the challenge of how to translate international experience and local $R \& D$ understanding into local policy certainty, to enable the birth of a first-of-a-kind technology (for South Africa). SAUCGA believes that UCG technology has reached a point where it now needs the guidance of:

a. A technology department, such as the DST. This will enable the cohesion of the various stakeholders (advocated in the first point) under the auspices of one department that can unite the vision and goals for UCG technology. An excellent precedent has been set by the developmental role the DST has taken in the shale gas industry.

b. A commercialization department, such as the DTI. This will enable the development of the financial and legal framework required to embrace a new technology.

3. Any technology involves risk, especially a new technology, for investors and regulators. SAUCGA proposes that government proceeds stepwise in regulating the industry, with for instance:

a. A consultative permitting and licensing framework with the close involvement of regulatory staff in the projects, to monitor, advise, and learn. The regulatory prerequisites could ratchet up to the levels expected from known technologies, based on the performance of the preliminary UCG installations. This will alleviate the current chicken-and-egg scenario that has evolved with, for example the Water Use License, where technology uncertainty precludes any further development.

b. Financial incentives (such as reduced royalties and taxes, or tax 'holidays') to encourage the nascent industry to grow.

\section{Acknowledgement}

The efforts and contributions of other SAUCGA members and collaborators in the compilation of the SAUCGA Roadmap must be commended. These are Dr R. Gumbi (Oxeye Energy), Professor F.B. Waanders (North-West University), Dr M Blinderman (Ergo Exergy), Mr E. Roberg (African Carbon Energy), and Ms T. Orford.

\section{References}

BARKER, O.B. 1999. A techno-economic and historical review of the South African coal industry in the 19th and 20th centuries, Part 1. Bulletin 113. Department of Minerals and Energy.

Blinderman, M. 2016. Personal communication [Interview].

CHoudhry, V. and Hadley, S. 1996. Utilization of lightweight materials made from coal gasification slags. Proceedings of Advanced Coal-Fired Power Systems' 96 Review Meeting, Morgantown, WV.

http://citeseerx.ist.psu.edu/viewdoc/download?doi=10.1.1.172.3837\&rep $=$ rep $1 \&$ type $=$ pdf

Couch, G. 2009. Underground Coal Gasification. CCC/151 ed. Clean Coal Centre, International Energy Agency, London:

Department of Energy. 2010. South African Integrated Resource Plan (IRP). Pretoria.

EXXARo Resources Limited. 2013.

Fossil Fuel Foundation. 2013. South African Coal Roadmap. Johannesburg.

Ginster, M. and MatjIE, R. 2005. Beneficial utilization of Sasol coal gasification ash. Proceedings of World of Coal Ash (WOCA), Lexington, KY, 11-15 April 2005. University of Kentucky Center for Applied Energy Research and the American Coal Ash Association. pp. 11-15.

Liu, S., LI, J., MEI, M., and Dong, D. 2007. Groundwater pollution from underground coal gasification. Journal of China University of Mining and Technology, vol. 17, no. 4. pp. 467-472.

Love, D. 2016. Towards closing the dirty water and carbon loops in cleaner UCG production. South African Underground Coal Gasification Workshop, Sandton.

Love, D., Aphane, V., vAN DER LINDE, G. and VAN ZyL, N. 2015a. Innovative approaches to predicting, mitigating and remediating groundwater pollution in UCG. SAUCGA, Secunda.

Love, D., Beeslaar, M., Blinderman, M., Pershad, S., van der Linde, G., and van DER RIET, M. 2014b. Ground water monitoring and management in underground coal gasification. Proceedings of the FFF Underground Coal Gasification (UCG) III Workshop, Johannesburg, South Africa, 28 August 2014. Fossil Fuel Foundation.

MinING WEEKLY. 2013. Underground coal gasification holds promise. http://www.miningweekly.com/print-version/underground-coalgasification-holds-promise-as-energy-source-sipho-nkosi-2013-08-19

Murugan, S. and Horack, B. 2016. Tri and polygeneration systems - A review. Renewable and Sustainable Energy Reviews, vol. 60. pp. 1032-1051.

National Planning Commission. 2010. National Development Plan 2030. Our future - make it work. Pretoria.

PerShAd, S. 2016. UCG - Eskom's experience and future projects. South African Underground Coal Gasification Association, Sandton.

Pershad, S. 2017. UCG within the South African context : Eskom's experience to date. Proceedings of the IEA Energy Efficiency and Emission Challenges Workshop, Kruger Park.

Smoli ski, A., Sta czyK, K., Kapusta, K., and Howaniec, N. 2012. Analysis of the organic contaminants in the condensate produced in the in situ underground coal gasification process. Water Science \& Technology, vol. 67. pp. 644-650.

Smoli ski, A., Sta CzyK, K., Kapusta, K., and Howaniec, N. 2012. Chemometric study of the ex situ underground coal gasification wastewater experimental data. Water, Air and Soil Pollution, vol. 223. pp. 5745-5758.

Van der Riet, M., Beeslaar, M., Blinderman, M., Love, D., Pershad, S., and van DER LINDE, G. 2014. Groundwater monitoring and management in UCG. South African Underground Coal Gasification Association, Sandton. 